\title{
Regulation of Tertiary Education Institutions in Botswana: Issues and Options
}

\author{
Thabile A. Samboma \\ Associate Researcher \\ Botswana Institute for Development Policy Analysis (BIDPA)
}

\begin{abstract}
The Government of Botswana has, and continues to invest on tertiary education as the key driver to knowledge based society. Tertiary institutions have been entrusted with the provision of quality and relevant education. Regulation of tertiary institutions has become a global issue of concern mainly due to the pressures of stakeholder's needs and expectations. This paper therefore, raises practical issues that affect regulation of tertiary institutions. This study therefore, uses a desk-top approach, which relies heavily on secondary data from relevant sources and documentations related to issues on tertiary education in Botswana, in order to identify the challenges facing the tertiary education sector and come up with key policy implications and options to address the challenges. The paper observes that challenges do exist in tertiary institutions. One of the main challenges is fragmentation of regulatory bodies, and this has negatively impacted on education access, quality and relevance. This paper also proposes options to improve the tertiary education sector. It is therefore, vital that oversight institutions like Botswana Qualification Authority (BQA) and Human Resource Development Council (HRDC) ensure that the country's vision 2036 is realised. The paper proposes that a university act should be put in place to govern all universities and an independent Quality Assurance monitoring mechanism which will serve as an instrument to regulate universities.
\end{abstract}

Keywords: Tertiary education, Regulation, Tertiary institutions

\section{INTRODUCTION}

Worldwide higher education has undergone significant changes in recent decades, and governance in university education has become a global issue of concern. Higher education governance is a key policy issue of the 21st century (Kennedy, 2003) [1]. Similarly, corporate governance issues, in both the private and public sectors, have become a topical issue in the last two decades (Edwards, 2003) [2], due to the increasing pressure from the needs and expectations of stakeholders. According to Edwards (2000) [3], some governments have made changes on the legislature, and imposed the changes on public and private institutions so as to improve their governance arrangements. Interestingly, tertiary institutions are among those caught up in the international surge in governance of institutions (Dixon \& Coy 2007) [4]. Issues of regulation have long been matters of both public policy discussion and academic research, particularly in both developing and developed economies, as they tend to attract significant attention, especially in times of economic and social crises. Therefore, effective regulation is essential to provide accountability for public funds, protect the interests of students and safeguard the reputation of a nation's tertiary education sector.

Similarly, in Botswana tertiary education has undergone tremendous changes, as evidenced by the increase in government spending on tertiary education. Throughout the years, the education sector has been getting a larger share of the national budget. In the 2014/15 education sector was allocated P9.26 billion and the figure increased to P10.31 billion in 
2015/16 (BIDPA, 2016) [5]. Levy (2007) [6] points out that public money for private higher education is a major policy issue for government, public and private institutions. There has also been an increase in the number of both public and private tertiary institutions, coupled with increase in enrolment rates in tertiary institutions. Another new development is the establishment of the new ministry responsible for tertiary education, the Ministry of Education, Research Science \& Technology (MoERST) in 2016. Notwithstanding this, there are still some challenges facing the tertiary education sector. The main challenge is the fragmentation of regulatory bodies, which has impacted on education access, quality and relevance. This has resulted in higher unemployment rates, especially amongst the youth, since the market cannot absorb most of them citing lack of proper skills for the job market.

This study therefore, uses a desk-top approach, which relies heavily on secondary data from relevant sources and documentations related to issues on tertiary education in Botswana. The paper identifies challenges facing the tertiary education sector and proposes key policy directions and options to address challenges facing tertiary education sector in Botswana. The rest of the paper is organized as follows. The next section provides a brief background on tertiary education in Botswana. Section 2 the tertiary landscape in Botswana, including, regulatory institutional framework and policy and legal frameworks. Section 4 provides emerging issues in Botswana's tertiary education, while section 5 concludes the paper.

\section{BACKGROUND}

At its independence in 1966, Botswana was among the poorest countries in the world with per capita GDP of US\$70. However, the country transformed itself from a Least Developed Country (LDC) to an upper-middle-income country (UMIC) with a per capita GDP of US\$8,533 in 2011, through fiscal discipline and sound management (World Bank, 2015) [7]. The country has also maintained one of the world's highest economic growth rates since independence in 1966. Botswana's average economic growth between 1966 and 2008 was 8.7 percent (MFDP, 2010) [8]. Between 1966 to the late 1990s, Botswana was one of the world's fastest growing economies with average annual GDP growth rates above 10 percent [7]. This growth was accompanied by declining poverty rates from 59 percent in 1985/86 to 19.3 percent in 2009/10 (Statistics Botswana, 2013) [9]. Literacy rates have also improved from 34 percent in 1981 to 86.5 percent in 2014 (Statistics Botswana, 2016) [10].

Tertiary education in Botswana began in 1964 with the establishment of the University of Basutoland, Bechuanaland and Swaziland, which was subsequently, renamed University of Botswana, Lesotho and Swaziland (UBLS) with its campus in Roma, Lesotho. Following the dissolution of UBLS in 1975, Botswana and Swaziland established the University of Botswana and Swaziland (UBS). They built university colleges in Gaborone and Kwaluseni, in Botswana and Swaziland respectively. In 1982, UBS was dissolved, and the University of Botswana (UB) was established (Malete \& Kobedi, und) [11]. Since its establishment, UB has been the only operational public university for a long time before the establishment of the second and third public universities, Botswana International University of Science and Technology (BIUST) in 2008 and Botswana University of Agriculture and Natural Resource (BUAN) in 2013.

Botswana, though a late entrant into the private tertiary industry, is a good illustrative example of this fast growing phenomenon. In practical terms, Botswana liberalised its tertiary education industry within the last decade. Ever since the implementation of the liberalisation policy, the rapid development in the private higher education sub-sector perfectly fits into what Mabizela (2007) [12] aptly described as private surge amid public dominance in the provision of higher education in Africa. 
Since then, Botswana has witnessed a proliferation of private tertiary institutions, as the demand for tertiary education in local institutions rose over the past decade. By the end of financial year 2014/15 a total of 40 Tertiary education institutions (TEIs) were registered of which 24 were public and 16 were private and collectively registered 60, 583 students (HRDC, 2015) [13]. Of note is the fact that, the Government of Botswana (GoB) ceased external sponsorship of tertiary students effectively in 2006. Through the "Study in Botswana initiative", the Government encouraged students to study locally and also called on local universities to offer more programmes (The Voice, 2014) [14]. Almost all private institutions experienced upsurges in the number of students who enrolled with the Botswana tertiary education system between 2008 and 2015. Strategic prioritization by Government, with a deep focus on encouraging greater private participation has had the major impact in gradual high levels of student enrolment recorded at private institutions to date [13]. However, simply providing access to higher education is not enough, since this has not translated into employment opportunities of the youth, as evidenced by high unemployment rate amongst the youth.

\section{Education Reforms}

In efforts to improve the education system the government undertook two major educational reforms. The first reform was in 1977 which produced a report entitled Education for Kagisanyo or 'Education for Social Harmony', so called because its main focus was on ensuring basic education for the majority of the then semi-literate population. The second reform introduced the Revised National Policy on Education (RNPE) of 1994, which called for a comprehensive strategy for education and training that would serve the human resource development needs of Botswana in the $21^{\text {st }}$ century (Republic of Botswana, 1994) [15]. The RNPE laid the foundations for current reforms in tertiary education and in several other areas of the education and training sector. The RNPE informs the overall policy on education in Botswana and the government accepted the commission's recommendations for the establishment of TEC, whose mandate was to oversee the development and long-term planning of the tertiary education subsector (MoESD, 2008) [16]. The establishment of TEC brought about a clear and distinct policy on tertiary education with defined goals and expected outcomes.

In line with [15], in 1997 the presidential Task Group came up with strategies and vision pillars for the year 2016. Among the pillars of interest to the study are "An educated and informed nation" and "A productive and innovative nation" (Republic of Botswana, 1997) [17]. The first pillar puts emphasis on the improvement of quality education and the adaptability of the adversity of the changing corporate world hence, the need for the education system to empower citizens to become entrepreneurs. The latter pillar calls for creativity and technological intensity. To achieve these goals, several factors but mostly building competent human resource base is required. This therefore, requires partnership of the public and private sector so that tertiary education provides graduates with job-relevant skills to meet the demands of firms and the economy as a whole (Bawakyillenuo et al., 2013) [18].

Tertiary education in Botswana is provided by universities, university colleges, technical colleges, brigades and other post secondary training institutes. Following government's recent decision to rationalise ministerial portfolios, the responsibility of tertiary education provision is now under the Ministry of Education, Research Science \& Technology. Tertiary education is divided into public and private tertiary institutions. Within this dichotomy, institutions are further categorized as universities, colleges and technical colleges. In these categories, are subcategories classifying the autonomy of public tertiary institutions. For instance, amongst public 
tertiary education providers, there are public-autonomous and public non-autonomous education institutions. Public autonomous institutions include: the University of Botswana (UB) established in 1982, Botswana International University of Science and Technology (BIUST) which was established in 2008 and Botswana University of Agriculture and Natural Resource (BUAN) in 2013. They are created by a statute and are run by boards of directors or university councils, while the non-autonomous public institutions are run by parent ministries.

The non-autonomous institutions are spread across the entire spectrum of ministries. For example, the Wildlife Training Centre is run by the Ministry of Environment, Natural Resource Conservation and Tourism; the Institutes of Health Sciences are with the Ministry of Health and Awareness (MoHW), while the Botswana Public Service College is run by the Ministry of Justice Defense and Security and the Madirelo Training and Testing Centre is run by Ministry of Employement, Labour Productivity and Skills Development (MELPSD). Government made a decision to bring all academic or training institutions under the then Ministry of Education and Skills Development (MoESD) in almost all cases. The government has expanded UB, introduced new programmes like the medical school and the establishment of a second public university in Palapye BIUST and BUAN in Gaborone which is expected to increase enrolment rates, especially in research science and technology fields. The assumption is that with a science and research based university the education sector will fulfil the mandate of Tertiary Education policy of 2008 (MoESD, 2008) [16] and the Vision 2036, which advocates for a knowledge based economy (Republic of Botswana, 2016) [19].

\section{Tertiary Education Landscape in Botswana}

Botswana's tertiary education system needs to be understood within the relevant context of the process of globalisation and the national agenda for transformation as represented by Vision 2036, which provides a series of trends, and pressure for reform. The compact of global and national demands are manifested in terms of the need for a more comprehensive definition of tertiary education, and the changing role of the state as regards to its direction and control of tertiary education institutions. Tertiary education in Botswana has a highly centralised structure, such that, tertiary education is seen as the responsibility of the MoERST and other central government ministries or agencies. Tertiary education in Botswana evolved into a dualistic system comprising of both public and private tertiary institutions where the latter is fast approaching the former.

\section{Management structure}

Institutional Governance of tertiary institutions in Botswana tends to vary in terms of structure. The management structure of some private universities have adopted the non conventional and business like management structure where the Chief Executive Officer (CEO) of the institution is called managing Director or Executive Director (Obasi, 2007) [20]. Public universities have adopted the conventional structure of management where there are structures that have university council, the senate and vice chancellors. Conflict usually arises in the non convectional universities between non academic and academic counterparts that occupy management positions as a result of the perceived structural abnormality caused by locus of power which appears to reside with the non academic management staff that was running the institute as pure business entrepreneurs [20].

\section{Regulatory Institutional Framework}

\section{The Ministry of Tertiary Education, Science Research \& Technology}

The newly formed Ministry of Tertiary Education, Science Research \& Technology is the bigger body in terms of governance of tertiary institutions and it is the first of its kind in Botswana 
since independence. The ministry handles tertiary education policy in general, as well as coordinating research, science and technology development to transform Botswana into knowledge based economy, while producing graduates that are relevant to industry requirements. Since independence at 1966, tertiary education in Botswana has been neglected, there has never been a ministry focusing on tertiary education before the newly formed one. The development of tertiary education is based on having a skilled nation that is in a position to contribute towards the country's realisation of its national development objectives.

The importance of tertiary education regulatory agencies cannot be over emphasised. Without such agencies there would be chaos in the tertiary industry especially in this era of globalisation where a lot of commercial tertiary entrepreneurs are more after profit than quality in the services they provide [20]. As a regulatory measure, the Government of Botswana $(\mathrm{GoB})$ has established some quality assurance and regulatory bodies which are parastatals notably, Botswana Qualification Authority (BQA) and Human Resource Development Council (HRDC).

\section{Human Resource Development Council (HRDC)}

The HRDC is an independent statutory body, which has the executive responsibility for national human resource development. It works closely with the Ministry of Tertiary Education, Science Research \& Technology in ensuring that the right skills are produced in the country. Mbuya (2017) [21] stated that HRDC promotes coordination and approval of institutional plans for both the private and public institutions and institutional capacity building. Through the adoption of the Human Resource Development Council Act No. 17 of 2013 by parliament, GoB established the HRDC, which became operational on 8 November 2013, effectively replacing the Tertiary Education Council (TEC). Before the establishment of HRDC, TEC was responsible for registration of higher education institutions, accreditation of courses, quality assurance of programmes of learning, planning and research, advisor to government, policy initiation, human resources planning and development and budgeting (Bailey \& Chirwa, 2014) [22].

\section{Botswana Qualification Authority (BQA)}

The Botswana Qualification Authority (BQA) is the de facto regulator of tertiary institutions as it is also there to set criteria for development of national education and training quality and inspection standards [21]. Before it was called BQA, it was The Botswana Training Authority (BOTA) which was established in 2000 under the Ministry of Labour and Home Affairs through the Vocational Training Act No. 22 of 1998 to ensure that quality skills were supplied to industry (HRDC, 2014) [23]. It was unfortunate that the quality of some skills produced did not meet the needs of the industry that is why the government established the regulatory bodies to monitor such. At some point BOTA and TEC mandates overlapped. This overlap called for separation of the two which led to HRDC and BQA [23]. With effect from 2013, BOTA continued under the new names of the BQA. The objectives of BQA are to provide for and maintain the National Credit and Qualifications Framework (NCQF) and to coordinate the education, training and skills development quality assurance system (MoESD, 2013) [24].

\section{Policy \& Legal Framework \\ The Tertiary Education Policy (TEP)}

The tertiary education system in Botswana is guided by the Tertiary Education Policy (TEP) of 2008, which also puts emphasis on the development of citizenry towards a knowledge based economy [16]. It is one of the strategies that were employed towards attaining one of the pillars of the Vision 2016 being "An Educated and Informed Nation". The TEP recognises 
tertiary education as a driver for development which is reflected in Figure1 (MoESD, 2010) [25]. Pavel (2012) [26] stated that when one has tertiary education they are likely to advance in life especially when they get better paying jobs, which comes with lots of health benefits and pension during old age. Furthermore he stated that governments spending on tertiary education bears fruits at both economic and societal level. Tertiary education benefits the economy through the formation of human capital and building knowledge base which is usually done through research and development. Lastly people with higher degree are appreciated by the society as they tend to follow the societal norms and seldom indulge in anti social behaviour, [26]. The 2008 Tertiary Education Policy emphasised tertiary education as a driver for development by stating explicitly its recognition that tertiary education has a significant role to play in ensuring Botswana's successful transition from being a resourcedriven economy to a diversified economy that is characterised in terms of a highly skilled knowledge-intensive service sector. The World Bank (2011) [27] also notes the importance of a knowledge based economy for sustainable development premised on higher education. Tertiary education has therefore become central to this development agenda.

Figure 1: Tertiary Education: - A driver of development

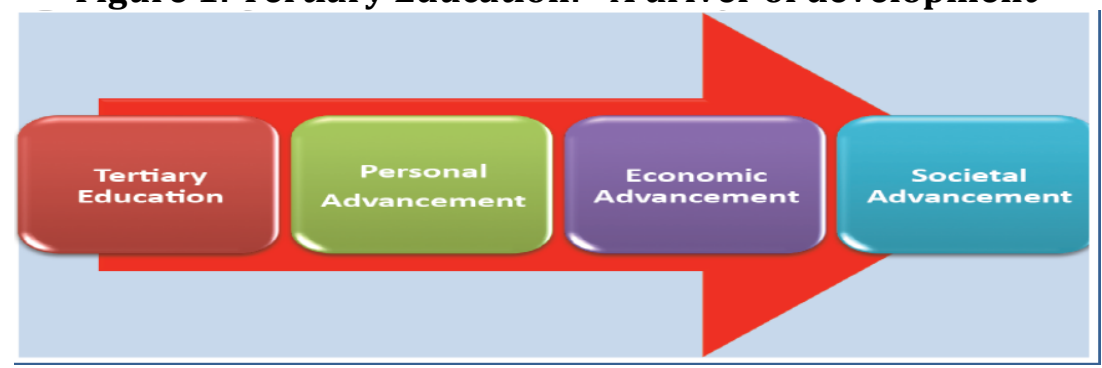

Source: MoESD (2010)

\section{Tertiary Education Act [Cap 57:04]}

The Tertiary Education Act established the TEC in 1999 with a mandate to formulate policy in tertiary education and oversee its management and development (BTEC, 2008) [28]. In 2013, TEC was replaced by HRDC, and provided for its powers, functions and duties in relation to the establishment and registration of tertiary education institutions (BIUST, 2008) [29]. In terms of the Act, the role of TEC, with respect to the accreditation and the establishment of public tertiary institutions, was merely advisory. Similarly TEC was given the responsibility to formulate policy on tertiary education and advise Government accordingly. In terms of the Act, read with section 14 of the Public Authorities (Functions) Act [Cap 02:11], the ultimate decision to establish or de-establish any public tertiary institution resides with the Minister responsible for tertiary education. It is the statutory HRDC mandate to advise the Minister with respect to tertiary education issues, including on the establishment of Public tertiary institutions.

\section{Emerging Issues in tertiary education sector}

While the BQA regulatory mandate requires all tertiary institutions, both public and private to adhere to its quality principles, the primary focus of the quality assurer appears to target mostly private providers (Sunday Standard, 2015) [30]. However the issue mentioned above is not surprising because, before the establishment of HRDC, while it was still TEC, it had the jurisdiction over private tertiary education institutions only, and that meant, main public institutions, such as the University of Botswana, the Botswana Accountancy College,the then Botswana College of Agriculture and BIUST, were not under direct supervision for the registration and quality assurance of their programmes. This meant that TEC's mandate, which included coordination of tertiary education sector, was hampered. Rather than the tertiary 
education sector, having an overall coordinating function, executed by TEC, the regulator had only partial regulatory power. Such regulatory power meant that the tertiary education sector lacked an overseer who can coordinate the roles and functions of public tertiary players [29].

According to Otlogetswe (2016) [31], when an institution wishes to run a programme, they apply to BQA with relevant documents such as the curriculum and other supporting details. Their application is then sent to about two reviewers who then pronounce whether such a program can be taught. Reviewers usually include an expert from the field and one who is an educator in the same field of the proposed programme. Once the reviewers recommend that a programme can be offered, an institution will go ahead and start teaching. It becomes an issue of concern when the programme starts without BQA knowing if the right lecturers are on the ground, without knowing if the library (if it exists at all) has the appropriate books to support the teaching of such a programme, without knowing if the classrooms and lecture theatres, labs etc are functioning.

Despite the BQA having a database of subject matter experts BQA acknowledges that the limited number of subject matter experts, may compromise quality in institutions .BQA still encounters few isolated cases where some Education Training Providers (ETPs) employ trainers who are not accredited and this is said to be attributed to the high mobility of trainers in the system [31]. One of the flaws of the domestic regulatory regime is that they dwell more on the regulation and development of the sector at large instead of enhancing accountability and quality improvement for the benefit of the student [18]. Students in tertiary institutions especially private ones have occasionally voiced out their concerns publicly concerning many issues that affect a student life. It is has become a common practice that students from various institutions often complain of unaccredited courses, interestingly the Ministry of Tertiary Education, Science Research \& Technology stated that some programmes that students have enrolled in, are not fully accredited. He highlighted that some of the programmes that are not accredited; it is as a result of product transition of the past regulations that allowed students to enrol for programmes which could be provisionally accredited, approved but not yet accredited [31].

Regulatory bodies are centralised in the capital city of Gaborone, this can be a hindrance as there is no close monitoring of institutions around the country. There seems to be lack of transparency on the institutions as there is little or no information sharing on issues that are of interest to both students and the nation at large to help them make informed decisions.

\section{CONCLUSION AND RECOMMENDATIONS}

Tertiary education across the world and in Botswana has undergone tremendous changes and governance and regulation of tertiary education has become a topical issue. The government of Botswana has, and continues to invest on tertiary education as the key driver to knowledge based society. Recently tertiary education in Botswana has been exposed to the impact of numerous social changes, and in particular to the phenomenon of mass access to tertiary education, government funding to both private and public institutions. It is now evident that, a large and growing sector of post-modern society has the need and aspiration to become involved in university affairs, especially in relation to the training of university professionals as well as accountability of institutions especially that funding has been extended to both public and private institutions.

Notwithstanding this, this paper observed that challenges do exist in the tertiary education sector, the main one being fragmentation of regulatory bodies, this has impacted negatively on 
education access, quality and relevance. While there is BQA and HRDC, This paper proposes that an essential function to support a sustainable education sector is an independent quality assurance and monitoring mechanism to evaluate the performance and program outcomes of both private and public education providers. Such a system could provide independent, unbiased assessments of the performance of educational institutions in both sectors, using the same standards and criteria for both. Well-designed quality assurance mechanisms can provide valuable information to consumers, providers, and government officials. It is of paramount importance to have effective internal monitoring systems, as there is need to cultivate the capacity for evaluation and accountability from within.

"The study in Botswana initiative" was government's idea, which has resulted in an increase in the student enrolment and number of institutions across the country. While there is mass enrollment country wide, the study has shown that regulatory bodies are centralized in Gaborone. A lot is happening in institutions some issues are unnoticed and unreported. It is necessary to decentralize regulatory bodies like BQA and HRDC for effective monitoring of institutions across the country. Lastly, there is need to have a university act which will focus on universities ensuring that there is standardization of operation in private and public universities. Such law will deal with the discrepancies that are found in universities like management structures of the two types of institutions (private and public). Tertiary institutions should enhance transparency by developing and publicizing information about their services.

\section{References}

Kennedy, K. J. (2003). Higher Education Governance as a Key Policy Issue in the 21st Century. Educational Research for Policy and Practice, 2(1), 55-70.

Edwards, M. (2003). Review of New Zealand Tertiary Education Governance. Wellington: Ministry of Education. Edwards, M. (2000). University Governance: A Mapping and Some Issues, paper presented to Life Long Learning Network National Conference. Melbourne, Australia.

Dixon, K., \& Coy, D. (2007). University Governance: Governing Bodies as Providers and Users of Annual Reports. Higher Education, 54(2), 267-91.

Botswana Institute for Development Policy Analysis (BIDPA). (2016). Botswana Government Budget: Briefing Note. Gaborone: BIDPA.

Levy, D. C. (2007). A Recent Echo: African Higher Education in an International Perspective. Journal of Higher Education in Africa, 5 (2), 197-220.

World Bank. (2015). Botswana Poverty Assessment. Report No. 88473-BW. Washington DC: World Bank. Ministry of Finance and Development Planning (MFDP). (2010). National Development Plan 10. Gaborone: MFDP. Statistics Botswana, (2013). Botswana Core Welfare Indicator Survey 2009/10 Final Report. Statistics Botswana, Gaborone.

Statistics Botswana. (2016). Selected Statistical Indicators 1966-2016: Enabling Stakeholders Formulate Policies, Plan and Make Decisions. Gaborone: Statistics Botswana.

Malete, L, \& Kobedi, K. (und) Botswana Country Profile.

Mabizela, M. (2007). Private Surge Amid Public Dominance in Higher Education: The African Perspective. Journal of Higher Education in Africa, 5(3), 15-38.

Human Resource Development Council. HRDC. (2015). Tertiary Education at a Glance. Gaborone: HRDC.

The Voice. (2014). Study In Botswana Policy Saves Government Millions. Gaborone: The Voice.

Republic of Botswana. (1994). Revised National Policy on Education of 1994. Gaborone: Government Printer.

Ministry of Education and Skills Development (MoESD). (2008): Towards A Knowledge Society. Tertiary Education Policy. 
Republic of Botswana, 1997. Long Vision 2016 for Botswana: Towards Prosperity for All. Gaborone: Government Printer

Bawakyillenuo, S., Osei Akoto, I, Ahiadeke, C., Aryeetey, E., Agbe, E. (2013). Tertiary Education and Industrial Development in Ghana. Policy Brief, 33012. Institute of Statistical, Social and Economic Research (ISSER). University of Ghana: Legon

Republic Of Botswana. (2016).Vision 2036. Achieving Prosperity For All. Gaborone: Government Printers. Obasi, I. N. (2007). New Private Universities in Nigeria. International Higher Education, 45, 14-15.

Mbuya, T. (2017). The decline and fall of higher education in Botswana: Quality assurance authorities conflict (Part two). Gaborone: Sunday Standard.

Bailey, T. \& Chirwa, D. (2014). The Roles \& Functions of Higher Education Councils \& Commissions In Africa: A Case Study Of The Botswana Tertiary Education Council.

Human Resource Development Council. HRDC. (2014). Annual Report. Gaborone: HRDC.

Ministry of Education and Skills Development (MoESD). (2013). Botswana Qualifications Act no 24 of 2013. Gaborone: MoESD.

Ministry of Education and Skills Development (MoESD). (2010). Driving the Transformation Agenda - Tertiary Education Sector Strategy 2009-2016.

Pavel (2012). The Importance of Quality in Higher Education in An Increasingly Knowledge Driven Society. International Journal of Academic Research In Accounting, Finance \& Management Science. 2(1), 120-127

World Bank (2011). World Development Report 2009/2010. Oxford University Press: New York.

Botswana Tertiary Education Council (BTEC). (2008). Accreditation Regulations. Ministry of Education and Skills Development (MoESD).

Botswana International University of Science and Technology (BIUST). (2008). BIUST Review. Unpublished Report. Gaborone: BIUST.

Sunday Standard. (2015). The Role Of The public \& Private Sector Education Institutions: A Response to Sunday Standard. Gaborone: Sunday Standard.

Otlogetswe, T. (2016). The State of Botswana Tertiary Education Capture: Part Two: The Botswana Qualifications Authority (BQA) problem. Gaborone: Sunday Standard.

\section{DISCLAIMER}

The views expressed in this paper are solely of the author and do not reflect the views of the Botswana Institute for Development Policy Analysis (BIDPA), where the author is employed. Therefore all errors and omissions remain that of the author. 